\title{
Designing for Networked Collaborative Discourse: An UnLMS Approach
}

\author{
Bodong Chen ${ }^{1, *}$ \\ ${ }^{1}$ University of Minnesota, USA \\ *chenbd@umn.edu
}

\begin{abstract}
Supporting collaborative discourse with discussion forums in a typical Learning Management System (LMS) remains challenging. This article reports on a design case of an "unLMS" approach, which aimed to devise a networked learning environment not based on an LMS for collaborative discourse in an online course. To support such discourse, four design principles were proposed based on the literature and then used to guide technological and pedagogical designs. Following the principles, a networked learning environment was configured by harnessing emerging technologies of open textbooks, web annotation, and team communication. The designed environment was piloted in the online course. A survey was distributed at the end of the course to investigate student perceptions of the design. Student perceptions of the environment was overall positive in terms of usefulness and ease of use, despite several suggested refinements to improve the tool integration and to personalize student discourse experiences.
\end{abstract}

APA Style citation: Chen, B. (2018). Designing for networked collaborative discourse: An unLMS approach. TechTrends, 1-8. https://doi.org/10.1007/s11528-018-0284-7

\section{Introduction}

Educational technologists have come up with many metaphors for the learning managements system (LMS), including a walled garden with many tools but not good at communicating with the external world (Mott \& Wiley, 2009), a minivan with utility features but nothing intriguing (Hill, 2015), and a bus driven by someone else other than the end users (Downes, 2015). Despite the prevalence of LMS in higher education (Lang \& Pirani, 2014), it is often criticized for not meeting particular educational goals such as supporting learner dialogues (Brown, Dehoney, \& Millichap, 2015). While the LMS will remain broadly relevant, it indeed only represents one genre of digital learning environments given the increasingly complex terrains of digital learning (e.g., Ito et al., 2013; Siemens, 2011).

Researchers and practitioners have been experimenting to "unLMS"- -attempting to challenge the traditional dependence on the LMS by exploring emerging solutions that can better facilitate particular learning experiences in the classroom. Such efforts are long-standing and widespread, represented by examples such as using Web 2.0 technologies and text messaging to foster networked learning (Carpenter \& Green 2017; Tu et al., 2012). At the heart of the unLMS approach is to depart from the traditional focus of an LMS on management by the instructor, towards recognizing affordances in a broad set of tools for creating "an environment or ecosystem [with] a dynamic, interconnected, ever-evolving community of learners, instructors, tools, and content" (Brown, Dehoney, \& Millichap, 2015, p. 3).

The design case introduced in this paper represents an example, or a precedent (Boling, 2010), of the unLMS approach. In particular, when developing a new graduate-level course, in order to promote collaborative learner discourse, I, the course designer and instructor, chose to set up a networked learning environment based on recent technological innovations in open textbooks, web annotation, and team communication. This design case aims to provide "a description of a real artifact or experience that has been intentionally designed" (Boling, 2010, p. 2). In this description I attempt to focus on precedent building and attest to trustworthiness and reproduction as standards of rigor for design cases (Boling \& Smith, 2009). In the remainder of the paper, I introduce the design context, design goals, design principles, the designed environment, its enactment in an online class, and student perceptions of the design.

\section{The Design Context}

The design case was situated in an online graduate-level course on "Social Network Analysis in Education" at a large public university in the United States. The course attracted 15 graduate students from four departments in the college, one of whom was participating from overseas. 
At the moment of the design, I, the teacher-designer, was a faculty member teaching and researching educational technology at this university. Prior to teaching this course, I had taught multiple online and face-to-face classes and had participated in a number of university-level pilots related to LMS, digital book platforms, and teacher dashboards. Overall, I had academic preparation in instructional design and had been actively exploring various digital learning environments in my teaching career.

\section{The Design Goal: Fostering Networked Collaborative Discourse}

Digital pedagogy is important because it is willing to improvise, to respond to a new environment, to experiment. The digital pedagogue is not the same as an online teacher. The digital pedagogue looks at the options, refuses the limitations of the LMS, invites her students to participate in-indeed, create-networked learning. (Morris, 2013)

Positioning myself as a digital pedagogue (Morris, 2013), I chose to experimented with the unLMS approach in the online course to foster networked collaborative discourse. This design goal was aligned with the course's focus on the social aspect of learning; indeed, networked learning was no longer optional but imperative for a course on social networks. Below I explicate conceptual perspectives that informed the design goal.

Networked learning, in contrast with the broader term e-learning, is defined as "learning in which information and communications technology (ICT) is used to promote connections: between one learner and other learners; between learners and tutors; between a learning community and its learning resources" (Goodyear et al., 2005, p. 473). Networked learning emphasizes human-human interaction mediated by technology. Instead of centering learning on instructional materials, the learners themselves become resources of a networked-learning course, with their online interaction being "absolutely essential. . . rather than a highly desirable enrichment" for learning (Thorpe, 2002, p. 113).

Interaction in networked learning is spatiotemporally distributed on the web. This is partly because web objects that mediate networked interaction (such as electronic documents, forum posts, and multimedia artifacts) are distributed in various locations and accessed at varied time points. More importantly, the spatiotemporal distribution is propelled by pedagogical shifts emphasizing networks and connections (Anderson \& Dron, 2011). More focus is placed on the emergent formation of connections-between the learner and information, contacts, and resources-when the learning problem at hand is constantly changing (Siemens, 2005). A significant design challenge, hence, is to help the learner form, maintain, and adapt these connections in various web spaces. To this end, we need to provide learners multiple entry points to networked learning and encourage them to be reflexive of the shifting reality of learning.

Collaborative discourse is another key factor in this design case. Collaboration is defined as "a coordinated, synchronous activity that is the result of a continued attempt to construct and maintain a shared conception of a problem" (Roschelle \& Teasley, 1995, p. 70). In the context of collaborative problem solving, collaboration requires a "Joint Problem Space" so that students have a shared conception of the problem and actions towards solving the problem.

Informed by this conception, collaborative discourse in this design case is broadly conceptualized as a discourse practice where students engage constructively with each other's overlapping problem spaces. Even though learners may not necessarily converge on a single joint problem, their problem spaces are adjacent or overlap with each other. Collaborative discourse involves coordinated, social processes for learners to identify, communicate, and tackle their learning problems. Because of learners' varied conceptual interests, collaborative discourse relies on their willingness to make their ideas visible to others and mutually invest in each other's ideas. A significant challenge for sustaining such discourse is to reconcile the tension among divergent learner interests and to maintain one coherent discourse in a classroom. Intentional design is needed to provide unique pathways for learners while enabling them to contribute to and benefit from each other's ideas.

Typical LMSs — specifically threaded discussion forums packaged within LMSs_often fall short in supporting networked learning and collaborative discourse. Prior research has documented a myriad of pitfalls of using threaded forums for learner discourse. For instance, Hewitt (2005) laments premature abandonment of discussion topics caused by the learner's "single-pass discourse practices." Because participants of threaded discussions tend to make single passes of unread posts, threads without new posts are likely to die. The threading structure of forums also leads to branching and increasingly fragmented conversations, with repetition and duplication appearing in different threads (Thomas, 2002). These design attributes of traditional discussion forums tend to restrain ideas within threads, suppress idea movements across discursive contexts, and consequently hinder the emergence of higher-order organization of ideas (Scardamalia \& Bereiter, 2003). Because of the early abandonment, fragmentation, and inflexibility, many discussion threads end up underdeveloped, within which ideas are trapped and far from achieving their potential.

To foster networked collaborative discourse, we need to look beyond what is provided in a typical LMS. In particular, we need to provide opportunities for learners to interact with rich web objects in different spaces, contribute ideas from different contexts, and move ideas freely to serve varied, shifting learning purposes. Informed by these theoretical and technological perspectives, to support networked collaborative discourse I distilled the following design principles for my design context: 
1. Principle 1. Any web object can become an object of learning discourse. A traditional threaded forum is separated from the discussed objects or conceptual artifacts (Bereiter, 2002). A more powerful discourse environment allows the user to connect various web objects with the discourse. This connection goes beyond "copy-and-paste" to maintain connected web objects within their original contexts.

2. Principle 2. Instead of being trapped in silos, ideas can move across discourse spaces. Ideas shared in one discourse space (e.g., a discussion thread) are portable and can be flexibly moved to another space to serve emergent discursive goals. At the individual level, this principle supports reflection on and reuse of one's earlier ideas. At the group level, this principle facilitates collaborative discourse by enabling learners to incorporate peers' ideas to solve new problems.

3. Principle 3. The discourse, participated by learners with diverse interests, has multiple entry points and is perceived to be coherent. Discourse contributions can be made from different web spaces while still maintaining a sense of one coherent discourse. This principle maintains the spatiotemporal distribution of networked learning without undermining the sense of one coherent discourse.

4. Principle 4. Boundaries between different learning and discourse spaces (e.g., public vs. private, formal education vs. workplace learning) are to be crossed if not totally dissolved. While classroom discourse is usually treated as a private space, networked learning celebrates authenticity and connectedness. Networked learning constantly bridges different discourse spaces serving varied purposes (such as an online class and a Twitter hashtag used by a professional community). Connectedness can be enriched by supporting discourse of varied levels of publicity-e.g., private in a small group, public in a private classroom, public to external communities - and to hereby foster networked collaborative discourse.

\section{The Design Product: A Networked Learning Environment}

A networked learning environment was designed in line with these four principles. The designed environment included three networked components. Tool choice was made based on my prior experiences with a range of relevant tools, my own technical capabilities, and, more importantly, the alignment between each tool and the design principles. While description offered below focuses on technological designs, pedagogical supports were weaved into the course-e.g., in course orientation materials, instructional videos, and class discussions - to support the enactment of technological designs.

\section{Open Course Portal: A Gateway to Web Objects}

To replace an LMS's role in hosting course materials, I used a tool, Bookdown (https: / /bookdown. org/), for open textbook authoring and web hosting. With this tool, I could author content in a markup language known as Markdown, which then got rendered to webpages. Similar to using LMS for hosting course content, I provided on the Bookdown site links to an online textbook and selected web materials (e.g., journal articles), weekly instructional videos I recorded, and guidelines for weekly learning activities (Principle 1; see Figure 1). By hosting it as an open textbook, learners not formally enrolled could also follow this course, enabling two pathways of course participation (Principle 4) akin to a "dual-layer participation" approach in massive open online courses (Rosé et al., 2015).

\section{Social Annotation Tool: Networked Discourse Across the Web}

To foster discourse connected with course-related web objects (Principle 1), I chose Hypothes.is, an emerging social annotation tool designed to support interactivity on the web. In comparison with its predecessors and alternatives, Hypothes.is adheres to the Open Annotation Model and the Linked Data principles that promote interoperability among information system (Haslhofer, Simon, Sanderson, \& Sompel, 2011). Hypothes.is functions through a browser extension or a bookmarklet (Figure 2). After activating Hypothes.is in the browser, a learner can annotate any piece of text on a webpage with her own ideas, to which other learners could respond (Principle 1). Tags can be attached to a Hypothes.is annotation, enabling the aggregation of web annotations that are scattered across webpages through a tag (Principle 2). Because Hypothes.is adheres to the Open Annotation Model, annotations are uniquely identifiable and retrievable, allowing portability of ideas not widely supported in threaded discussion forums (Principle 2). The search functionality of Hypothes.is offers means to aggregate annotations according to a variety of criteria such as by tags, users, user groups, and annotated web URLs. Users are thus able to enter the discourse not only from a specific webpage (e.g., the textbook), but also from the search page that provides another view of the discourse (Principle 3).

In addition, to negotiate the public-private boundary, I allowed course registrants to annotate either in a private course group or in public - provided that everyone would use a same course hashtag (Principle 4). Using Hypothes.is, the class carried on weekly discussions across various web spaces, including the Bookdown course website, textbooks, journal articles, blog posts, and other web materials shared by me and students (Principle 1). In summary, the social annotation tool enabled a discourse - public and private—anchored in multiple types of web objects relevant to the course. 


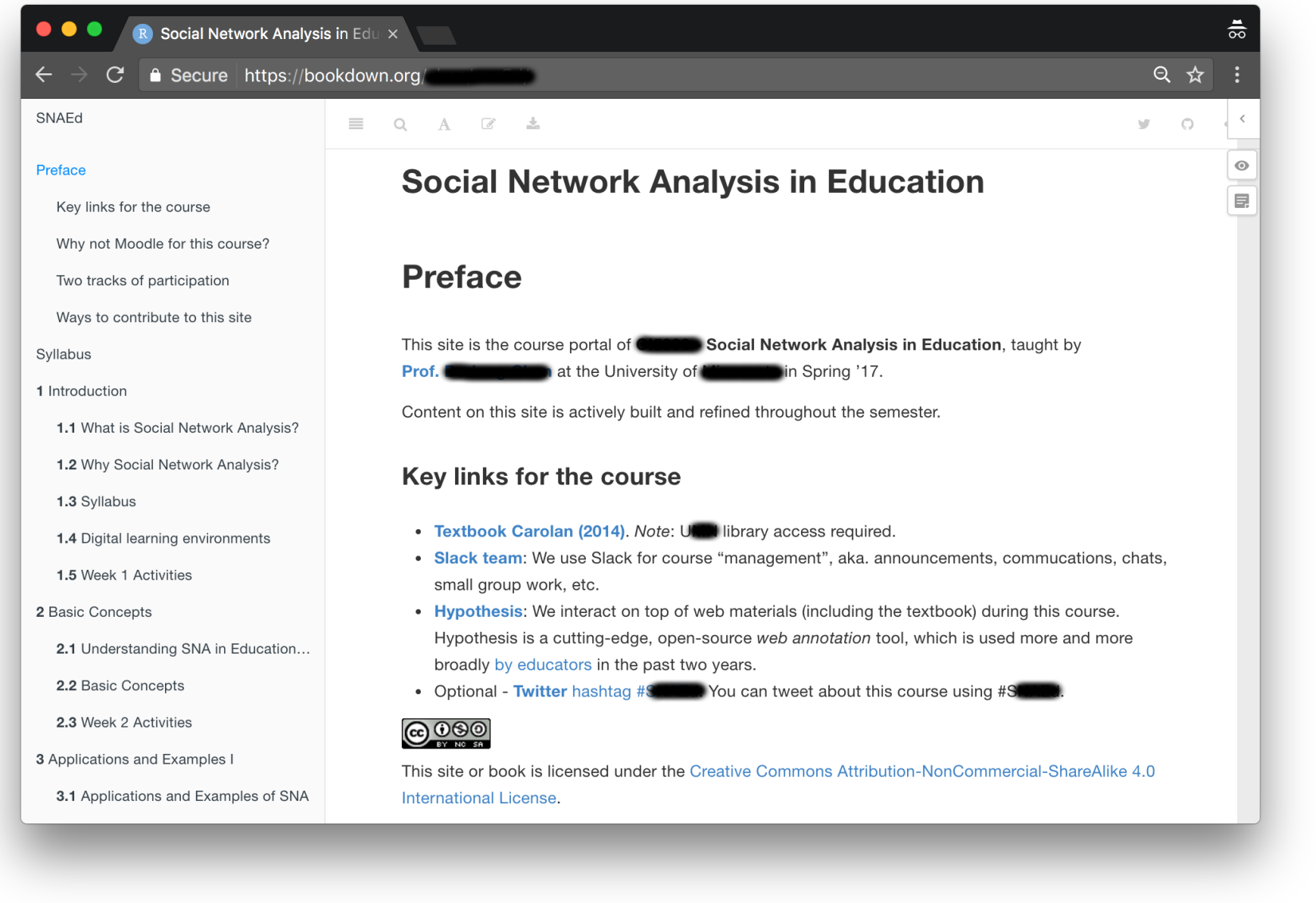

Figure 1. Open course portal hosted on bookdown.org

\section{Team Communication Tool: Collaborative Discourse in the Class}

To facilitate class communication and logistics, such as course announcements, Q\&As, and course assignments, I created a private Slack team for formal course participants. Slack is a team communication tool initially popular in startups and recently adopted by educators. Compared to traditional threaded forums, communication on Slack is free-flowing. Instead of having students posting in a thread each week, the class hosted several Slack channels for general purposes (such as discussing course concepts, submitting assignments, sharing "cool stuff"). The linear progression of discourse in each channel helps participants stay current with recent posts. Meanwhile, they can also share an earlier post to its current channel to revitalize it, or share to another channel to serve a different purpose (Principle 2). The user can also start a thread below a Slack message to preserve a meaningful discursive context while avoiding distractions to other members of the channel who may not be interested in this particular discussion (Principle 4). Overall, Slack provides means to rethink and refine boundaries set by traditional discussion threads.

In this design case, Slack is not merely a replacement of discussion forums. Its support for file sharing enables students to contribute various types of conceptual artifacts (e.g., an essay, a code snippet, a Google Doc; Principle 1) to the whole class, a specific channel, or a private conversation (Principle 4). Slack's open API brings about a wide range of plugins that serves various purposes including integrations with external tools (e.g., Hypothes.is, Twitter, chat bots). These affordances, many of which were untapped in this design case, offer promise in interoperability and personalization sought by the digital learning community (Brown, Dehoney, \& Millichap, 2015).

To support privacy and intimacy of formal course participants, the Slack community was set to private and not accessible to open participants (Principle 4). Learners submitted course assignments in a dedicated "assignments" channel and made their submissions visible to all Slack members. This design decision was made based on the course context where assignments were largely individualized based on each learner's problem spaces. So posting assignments publicly in the private Slack space would less likely jeopardize independent work but facilitate emergent collaboration among learners (Principles $2 \& 4$ ). Moreover, the class's Hypothes.is activities were synced into a dedicated Slack channel named "Hypo Feed" via the Hypothes.is API; web 


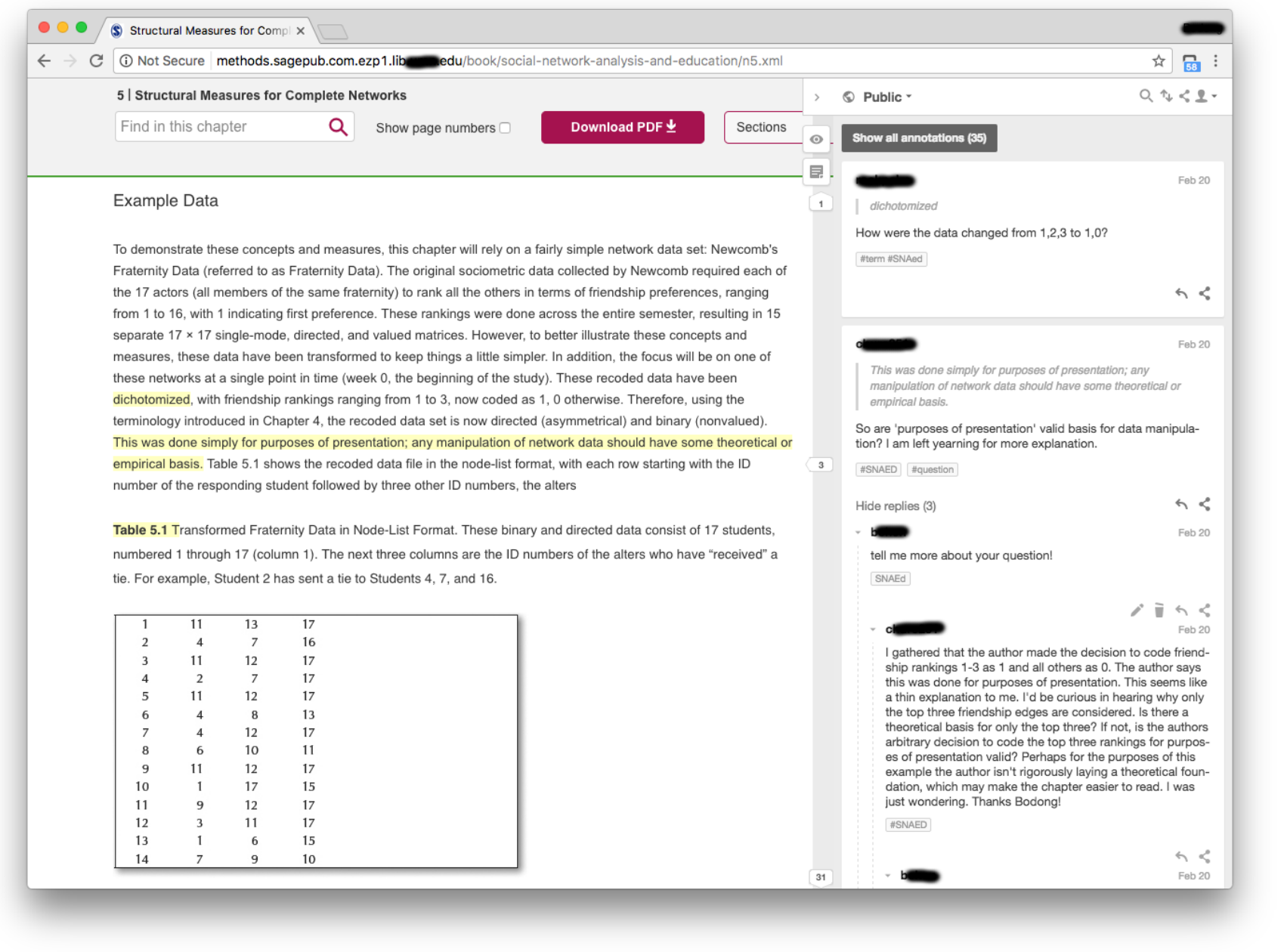

Figure 2. Annotating a book chapter using Hypothes.is. Fifty-eight annotations have been made on this page. On the left presents the textbook accessible online through the university's library. To the right is the Hypothes.is sidebar presenting existing annotations anchored in specific text snippets, which are highlighted to the left in the webpage

annotations containing the course hashtag were notified on Slack, allowing Slack participants to enter a specific Hypothes.is discussion via a web URL provided in the notification (Principles 2,3 \& 4).

To summarize, Table 1 shows how these three components collectively respond to the derived design principles. Overall, the Bookdown course website served as a portal linking various web objects with learners and enabled two pathways of course participation. Hypothes.is supported learner interactions on various web objects through web annotations, facilitated idea movement among discourse spaces, enabled the review and synthesis of the annotations, and promoted boundary-crossing between two participation pathways (i.e., open and private). Slack replaced traditional discussion forums and added rich support for participants to monitor the discourse, revitalize earlier ideas, repurpose ideas in the evolving discourse space, and collaborate on various adjacent problems. Integration between Slack and Hypothes.is was designed to support boundary-crossing between these two spaces via web URLs. Beyond these three tools, a standalone grade book was used to keep track of student grades, a feature commonly found in an LMS.

\section{Design Enactment and Student Perceptions}

The design was enacted in the aforementioned graduate-level class. Among 15 registered students, one was auditing, one withdrew, and another was inactive, leaving 12 active student participants. Over one semester, the class collectively made a total of 615 Hypothes.is annotations and sent 2,441 Slack messages; the Bookdown course website received 1,309 visits within the state and 703 from outside of the state. Two network visualizations in Figure 3 demonstrate social interactions that took place on Hypothes.is and Slack. Overall, interactions in both spaces were dense, forming more than $40 \%$ of all possible 


\begin{tabular}{|l|c|c|c|}
\hline Goals & Bookdown & Hypothesis & Slack \\
\hline 1. Any web object can become an object of learner discourse & $\mathrm{x}$ & $\mathrm{x}$ & $\mathrm{x}$ \\
2. Ideas can move across discourse spaces & & $\mathrm{x}$ & $\mathrm{x}$ \\
3. The discourse has multiple entry points and is perceived to be coherent & & $\mathrm{x}$ & $\mathrm{x}$ \\
4. Boundaries between different learning and discourse spaces are to & $\mathrm{x}$ & $\mathrm{x}$ & $\mathrm{x}$ \\
be crossed if not totally dissolved & & & \\
\hline
\end{tabular}

Table 1. Summary of tools and design goals

connections among students in each space. Student interactions were also decentralized (below 0.20 in both spaces), reciprocal ( 0.46 on Hypothes.is and 0.57 on Slack), and transactive (above 0.65 in both spaces). Student connections were stronger on Slack, as indicated by a higher average number of interactions per student on Slack (58.28) than on Hypothes.is (22.15). As perceived by the teacher-designer, discourse taking place in this course was (a) networked among multiple technological components, web spaces, knowledge objects, and individuals, and (b) collaborative given students' joint efforts in solving problems. Through the discourse, students were engaged in sensemaking, sensegiving, problem-solving, artifact creation, and deepening discussion around knowledge artifacts. Even though they were working on distinctive course projects, they collaborated in various manners including collectively unpacking key concepts, sharing data analysis codes, and critiquing each other's project findings. Despite its departure from a traditional LMS, the integrative system with multiple technological components was able to support meaningful student discourse.
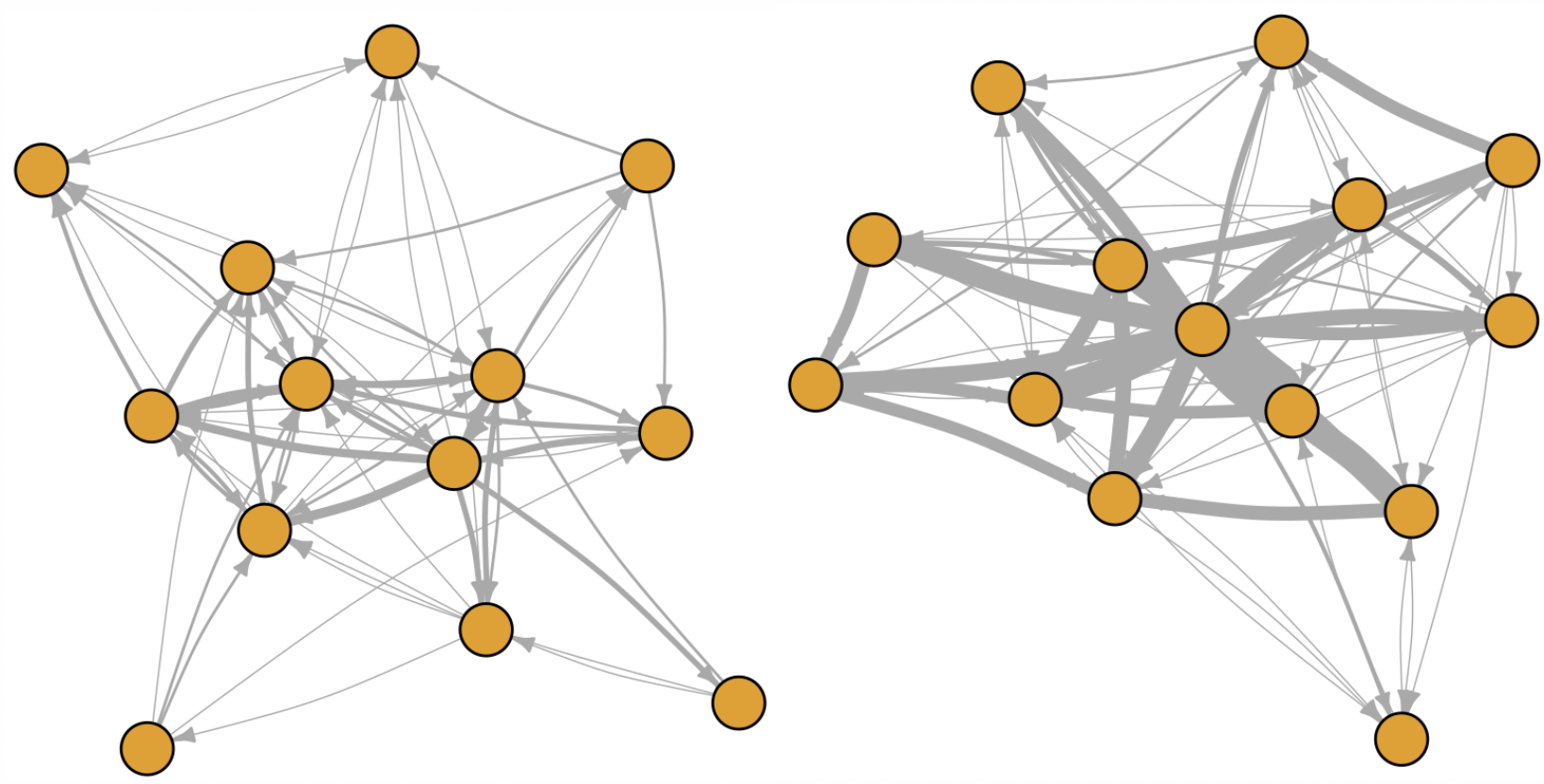

Figure 3. Visualizations of student interaction networks on Hypothes.is (left) and Slack (right). In each visualization, a node denotes a student, and each weighted directed edge indicates the existence and strength of interaction from one student to another

To investigate student perspectives, an online survey was distributed to the class in the final week. This survey included nine questions, six of which were matrix questions made of multiple Likert-scale items. The survey was organized into four sections: (1) students' prior experiences with the tools (Question 1, three 5-point Likert-scale items), (2) student usage of these tools during the class (Question 2, seven 5-point Likert-scale items), (3) student perception of the tools' usefulness and ease of use (Questions 3-6, 7-point Likert-scale items adapted from the Technology Acceptance Model [Davis, 1989]), and (4) open-ended suggestions on the design to inform the next iteration (Questions 7-9). Eight responses were received from formal course participants. Due to the small sample size, analyses of survey responses focused on themes that would inform future design instead of statistical procedures. 
According to received responses, students were the least familiar with Hypothes.is prior to the course, with seven students (out of eight) responding "1-Not at all familiar." Familiarity with Slack was more evenly distributed, as three students expressed moderate or extreme familiarity. Familiarity with open textbook technologies was in between.

Among affordances provided by the environment, the most heavily used ones included: Check announcements on Slack $(\mathrm{M}=4.13, \mathrm{SD}=1.05)$, Visit the Bookdown course website $(\mathrm{M}=4.13, \mathrm{SD}=0.78)$, and Annotate using Hypothes.is $(\mathrm{M}=3.75$, $\mathrm{SD}=0.43)$. Two moderately used affordances included Publicly interact with classmates on Slack $(\mathrm{M}=3.63, \mathrm{SD}=0.99)$ and Check the Hypothes.is feed on Slack $(\mathrm{M}=3.63, \mathrm{SD}=1.11)$. The least frequently used features included: Privately interact with classmates on Slack $(\mathrm{M}=3.13, \mathrm{SD}=1.27)$, and Reply to Hypothes.is annotations made by others $(\mathrm{M}=3.25, \mathrm{SD}=0.66)$. Notably, in terms of collaborative discourse, students more frequently relied on public conversations on Slack in comparison to private Slack messages and Hypothes.is replies. For example, one student commented that it was "motivating to see [public] peer comments [on Slack] and know that we are all working through these concepts together." But for peer interactions on Hypothes.is, one student said "Mostly I'd prefer to read and make notes on my own as opposed to as part of a class project, [unless] there's a particularly sticky reading."

In terms of usefulness and ease of use, first of all, students found the integration moderately useful $(\mathrm{M}=4.25, \mathrm{SD}=1.48)$ and easy to use (M=4.00, $\mathrm{SD}=1.50$; both on a 7-point Likert scale), indicating the need for future refinement. As one student responded, "The Hypo[thes.is] feed was hard to read and gave me too many updates." Another student suggested creating multiple "Slack channels to organize our Hypothes.is annotations" in future course iterations.

Table 2 presents student perceived usefulness and ease of use for both Hypothes.is and Slack. Overall, Slack was perceived to be more useful and easy to use than Hypothes.is. For example, one student commented that "Slack is great in its current state, while Hypothes.is could use a few tweaks." Based on student responses to open-ended questions, Hypothes.is was found useful for community building, collaborative sensemaking of challenging readings, and personal tracking of reference materials. However, one student was confused by the public and private annotation groups on Hypothes.is and another student who "was often the first person [to annotate weekly readings] didn't like having to go back to read comments a week later." Further efforts to fine-tune discourse design for different learner preferences would be helpful. In terms of Slack, students found it "motivating to see peer comments" and useful "for helping each other." Students enjoyed having various Slack channels created for them "to connect with each other in non-required ways (e.g., the R channel, general stuff, Q\&A, ideas)" and to "directly communicate with specific classmates without having to use a [public] community discussion board." However, a few students, especially those studying part-time, found Slack's fast-paced conversations overwhelming. As one student explained, "If you weren't on it for a couple days, there would sometimes be a huge backlog." Indeed, while meaningful collaborative discourse was taking place in the integrative environment, a variety of challenges remained to be addressed in future design.

\begin{tabular}{|l|c|c|}
\hline & $M$ & $S D$ \\
\hline Integration & 4.25 & \\
Perceived usefulness & 4.00 & 1.58 \\
Perceived ease of use & & 1.60 \\
\hline Hypothes.is & 5.13 & \\
Perceived usefulness & 5.44 & 1.01 \\
Perceived ease of use & & 1.11 \\
\hline Slack & 5.78 & \\
Perceived usefulness & 5.97 & 1.83 \\
Perceived ease of use & & 1.38 \\
\hline
\end{tabular}

Table 2. Means and standard deviations of student's perceived usefulness and ease of use

\section{Conclusions and Future Directions}

EDUCAUSE envisions a next generation digital learning environment that would support interoperability, personalization, analytics, collaboration, and accessibility for all learners (Brown, Dehoney, \& Millichap, 2015). This design case illustrates an effort towards such a vision through an unLMS approach. Development in educational technology in the past years has been challenging the concept of "learning management," catalyzing a shift from learning management systems towards learning environments or platforms that foster learning - learning of various kinds (Feldstein, 2017). This paper introduces an intentional design that focused on the integration of existing tools, which were originally designed for drastically different purposes, to synergically support learning through networked collaborative discourse. Overall, students perceived the discourse environment to be moderately useful and easy to use and provided valuable insights in ways to improve the integration and discourse experiences. 
Future efforts will be made to advance the unLMS approach and the presented design for networked collaborative discourse. First of all, an empirical study is ongoing to examine the nuanced collaborative discourse across multiple web spaces. We collected data from multiple sources (e.g., system logs) to tackle research questions regarding participation patterns, discourse qualities, and learner experiences. Second, the current design lacks an analytic system that can support students' sensemaking and wayfinding in such a networked and integrative system (Siemens, 2011). The need for learning analytics was echoed by several students who expressed difficulties with the fast-paced, spatiotemporally distributed online discourse. Using log data from Hypothes.is and Slack, I envision a suite of discourse analytics to assist the instructor and students in keeping track of their collaborative discourse and making informed decisions on when and how to contribute. Finally, as the course is to be offered again, I plan to maintain and reuse these digital spaces to explore cross-community interactions (Zhang et al. 2018). This effort is motivated by the current cohort's expressed desire to maintain the community and to re-engage with the course content. This continued design effort will attempt to challenge the artificial timeframes imposed by the academic calendar, so as to continually engage course alumni, nurture a sense of sustained community, and foster boundary-crossing across cohorts of students. When an LMS closes, learning could continue, so could connections formed in and for learning.

\section{Acknowledgements}

This paper was partially supported by an NSF Award (No. 1657009). I thank Ramya Sivaraj for her assistance in setting up the survey and Dr. Stian Haklev for commenting on an earlier draft of this paper.

\section{References}

- Anderson, T., \& Dron, J. (2011). Three generations of distance education pedagogy. The International Review of Research in Open and Distributed Learning, 12(3), 80-97 Retrieved from http://www.irrodl.org/index.php/irrodl/article/view/890/1826.

- Bereiter, C. (2002). Education and mind in the knowledge age. Mahwah, NJ: Lawrence Erlbaum.

- Boling, E. (2010). The need for design cases: Disseminating design knowledge. International Journal of Designs for Learning, 1(1), 1-8.

- Brown, M., Dehoney, J., \& Millichap, N. (2015). The next generation digital learning environment. EDUCAUSE. Retrieved from https://net.educause.edu/ir/library/pdf/eli3035.pdf.

- Carpenter, J., \& Green, T. (2017). Connecting and engaging with students through group me. TechTrends, 61(1), 89-92. https://doi.org/10.1007/s11528-016-0149-X.

- Davis, F. D. (1989). Perceived usefulness, perceived ease of use, and user acceptance of information technology. MIS Quarterly, 13(3), 319-340.

- Downes, S. (2015). Commentary on 'LMS is the minivan of education (and other thoughts from \#LILI15)'. OLDaily. Accessible from http://www.downes.ca/post/63849.

- Feldstein, M. (2017). A flexible, interoperable digital learning platform: Are we there yet?. e-Literate. Accessible from http://mfeldstein.com/flexible-interoperable-digital-learning-platform-yet/.

- Goodyear, P., Jones, C., Asensio, M., Hodgson, V., \& Steeples, C. (2005). Networked learning in higher education: Students' expectations and experiences. Higher Education, 50(3), 473-508. https://doi.org/10.1007/s10734-004-6364-y.

- Haslhofer, B., Simon, R., Sanderson, R., \& Sompel, H. V. de. (2011). The Open Annotation Collaboration (OAC) Model. In 2011 Workshop on Multimedia on the Web (pp. 5-9). IEEE. https://doi.org/10.1109/MMWeb.2011.21.

- Hewitt, J. (2005). Toward an understanding of how threads die in asynchronous computer conferences. Journal of the Learning Sciences, 14(4), 567-589. https://doi.org/10.1207/s15327809j1s1404_4.

- Hill, P. (2015). LMS is the minivan of education (and other thoughts from \#LILI15). e-Literate. Accessible from http://mfeldstein.com/lms-is-the-minivan-of-education-and-other-thoughts-from-lili15/.

- Ito, M., Gutiérrez, K., Livingstone, S., Penuel, B., Rhodes, J., Salen, K., et al. (2013). Connected learning: An agenda for research and design. Irvine, CA, USA: Digital Media and Learning Research Hub.

- Lang, L., \& Pirani, J. A. (2014). The learning management system evolution. EDUCAUSE Center for Analysis and Research. Retrieved from https://library.educause.edu//media/files/library/2014/5/erb1405-pdf.pdf. 
- Morris, S. M. (2013). Decoding digital pedagogy, part 1: Beyond the LMS. Hybrid Pedagogy. Accessible from http://www.digitalpedagogylab.com/hybridped/decoding-digital-pedagogy-pt-1-beyond-the-lms/

- Mott, J., \& Wiley, D. (2009). Open for learning: The CMS and the open learning network. In Education, 15(2). Retrived from https://scholarsarchive.byu.edu/facpub/113/.

- Roschelle, J., \& Teasley, S. D. (1995). The construction of shared knowledge in collaborative problem solving. In Computer supported collaborative learning (pp. 69-97). Springer, Berlin, Heidelberg. https://doi.org/10.1007/978-3-64285098-1_5.

- Rosé, C. P., Ferschke, O., Tomar, G., Yang, D., Howley, I., Aleven, V., et al. (2015). Challenges and opportunities of dual-layer MOOCs: Reflections from an edX deployment study. In Proceedings of the 11th International Conference on Computer Supported Collaborative Learning (CSCL 2015). Vol. 2 (pp. 848-851). Gothenburg: International Society of the Learning Sciences.

- Scardamalia, M., \& Bereiter, C. (2003). Knowledge building environments: Extending the limits of the possible in education and knowledge work. In A. DiStefano, K. E. Rudestam, \& R. Silverman (Eds.), Encyclopedia of distributed learning (pp. 269-272). Thousand Oaks, CA: Sage Publications.

- Siemens, G. (2005). Connectivism: A learning theory for the digital age. International Journal of Instructional Technology and Distance Learning, 1-8 Retrieved from http://er.dut.ac.za/handle/123456789/69.

- Siemens, G. (2011). Orientation: Sensemaking and wayfinding in complex distributed online information environments ( $\mathrm{PhD}$ thesis). In University of Aberdeen.

- Smith, K. M., \& Boling, E. (2009). What do we make of design? Design as a concept in educational technology. Educational Technology, 49(4), 3-17.

- Thomas, M. J. W. (2002). Learning within incoherent structures: The space of online discussion forums. Journal of Computer Assisted Learning, 18(3), 351-366. https://doi.org/10.1046/j.0266-4909.2002.03800.x.

- Thorpe, M. (2010). Rethinking Learner Support: The challenge of collaborative online learning. Open Learning: The Journal of Open, Distance and e-Learning, 17(2), 105-119. https://doi.org/10.1080/02680510220146887a.

- Zhang, J., Tao, D., Chen, M.-H., Sun, Y., Judson, D., \& Naqvi, S. (2018). Co-organizing the collective journey of inquiry with idea thread mapper. Journal of the Learning Sciences. https://doi.org/10.1080/10508406.2018.1444992. 